\title{
THE USE OF PRIMATES IN SCREENING DEPENDENCE LIABILITY
}

\author{
HenRY H. SwaIN \\ Department of Pharmacology, The University of Michigan Medical School, Ann Arbor, Michigan, USA
}

FIVE YEARS ago, I inherited from my predecessor a colony of 'junkıe monkeys', Macca mulatta rhesus monkeys that are kept physically dependent by giving them morphine sulfate, $3 \mathrm{mg} / \mathrm{kg}$ subcutaneously four tımes each day. For the past 25 years, this monkey colony has been used to evaluate the physical dependence hability of drugs of the morphine family. The colony has been one part of a structure, designed and operated by the late Nathan B. Eddy, for the purpose of keeping off the American market any dangerous, new addictive drugs. The American people, frightened for many years by the spectre of the drug-crazed dope fiend, is willing, from time to time, to give political support to programs for the control of drug abuse.

Nathan B. Eddy created such a program. It flourished during the 1930's but perished in the early 1940's during World War II. Immediately after that war, because of the knowledge that the Germans had invented mependine (pethidine), methadone and perhaps many other potent narcotic analgesics, Eddy's program was re-established and expanded. A committee, now known as the Committee on Problems of Drug Dependence, was established as an arm of our National Academy of SciencesNational Research Council (NAS-NRC). For all practical purposes, Eddy was the Committee on Problems of Drug Dependence In the name of the Committee, he collected money from pharmaceutical industry to support research activities. Over a period of two decades, much of that research money went to Ann Arbor, Michigan, where Maunce $\mathrm{H}$. Seevers used it to establish and maintain a colony of morphinedependent monkeys. The primary purpose of this colony was to prevent the overloading of the colony of human volunteer addicts at the Addiction Research Center at Lexington, Kentucky. By screening drugs first at Michigan, it was possible to channel the human resources to the most interesting and important drugs.

In order for a new drug (narcotic or otherwise) to be admitted to the American market, it must first be approved by our Food and Drug Administration. In the case of a narcotic drug, the FDA would not approve a drug unless it had been tested and recommended by the Lexington group. Lexington would not examine a new drug unless it had been evaluated for its physical dependence lability at the Michigan facility. This chain of evaluations was supervised by the Committee on Problems of Drug Dependence.

In practice, a manufacturer wanting approval of a new narcotic drug would submit a sample of it to the Committee, where Eddy (or his successors) would perform an analgesic evaluation using the mouse hot-plate test. Then some of the drug would be sent to Seevers at Michigan. It would be identified only by a code number and it would be accompanied by only a recommended starting dose and, occasionally, by suggestions for solubilizing the material Thus, Seevers and his colleagues never knew the source of a tested compound, its chemical structure, its metabolic fate or any other such information at the time that the drug was being tested.

The tests now used at The University of Michigan are essentially the same as they were in 1957 when the first unknown compounds were evaluated in the program Since that time, approximately 1000 compounds have been studied

The first step in the evaluation is always the Single Dose Suppression (SDS) The monkeys normally receive morphine four times every day, at 1 a.m., 7 a.m., 1 p.m and 
$7 \mathrm{p} \mathrm{m}$. However, about once a week, the anımals are put into abstinence by witholding two consecutive morphine doses. They receive the regular 7 p.m. dose but their $1 \mathrm{a} . \mathrm{m}$ and 7 a.m. injections are omitted. By 9 a.m., the animals are $14 \mathrm{hr}$ abstinent, and the test is ready to begin. At that point the monkeys are at a mid-point in the spectrum of the abstinence syndrome, which we grade on a scale created by Seevers and modified over tıme. On that scale, 0 signifies that there are no abstınence signs at all and 6 describes an animal so ill that there begins to be a danger of losing its life. The $14 \mathrm{hr}$ abstınent monkey is usually between grades 3 and 4 on the Seevers scale.

A dose of a drug to be tested is administrered subcutaneously at the 14th hour, and the severity of abstinence signs is evaluated periodically for the next $4 \mathrm{hr}$, until it is tıme for the next regular morphine injection $(1 \mathrm{p} \mathrm{m}$.). Under these conditions, if the test drug is:

(a) ineffective-the abstınence signs will continue to develop, so that by the end of the four-hour observation period the animal will be between 4 and 5 on the Seevers scale;

(b) morphine like-the abstinence signs will become less severe and, if the dose is sufficient, suppressed all together. Stıll larger doses cause morphine-like CNS depression, stupor and even respiratory depression. The time of maximum effect vanes from compound to compound, but is usually between 1 and $2 \mathrm{hr}$ after administration,

(c) a narcotic antagonist-the abstınence syndrome promptly becomes more severe;

(d) a CNS depressant not of the morphine type-the monkeys show sedative, hypnotic and related effects without appreciable change in the abstinence signs-a distinction which can be made by an experienced observer

Related tests are used as appropriate. Non-withdrawn anımals are used when the test drug seems to be a narcotic antagonist (because it increases the severity of signs in the SDS test). In this test, the monkeys receive their regular morphine doses until $2 \mathrm{hr}$ before the test drug is given. Therefore, in the non-withdrawn test, the animals start at 0 rather than at 3 or 4 on the Seevers scale. Even quite weak antagonists produce visible abstınence sıgns in non-withdrawn, morphıne-dependent monkeys.

Normal (non-dependent) monkeys are used occasionally for one of two purposes: (a) to see whether naloxone will reverse the depressant actions of a single, large dose of the test drug, and (b) to determine whether the test drug (if it seems to be an antagonist) will antagonize the depressant actions of a sıngle large dose of morphine or meperidine.

Oral administration is employed occasionally by passing a gastric tube in a chairrestrained monkey, and delivering the drug via the tube as either a solution or a suspension.

Twenty-four-hour substitution involves the replacement of not just a single morphine dose but of a whole day's morphine by giving repeated doses of the test drug. This may prove useful when the Single Dose Suppression test gives equivocal results in which it is unclear whether the partial suppression of abstinence signs is specific (morphıne-like) or nonspecific. If the suppression is nonspecific, the abstinence signs will continue to grow more severe in spite of repeated administration of the test drug.

It is possible for a drug to be a narcotic-type agonist and still not produce complete suppression of abstinence signs in the Single Dose Suppression, if the acute toxicity of the drug precludes giving a totally effective dose. Convulsions are by far the most common dosage-limiting acute toxic sign with this family of drugs. In fact, one can conclude that all narcotics are convulsants but there is a large range, among compounds, in the ratio between the abstinence-suppressing dose and the convulsant dose. At one end of this range is morphine, for which the convulsant dose is so relatively large that in the monkey (and in man) convulsions are seen only under very special curcumstances. At the other end of this range are such well-known drugs as codeine and propoxyphene, for which the convulsant dose is actually less than the dose required to completely suppress abstinence signs.

Species differences to the actions of morphine are well known, but it is not always appreciated that a well-developed morphine-abstinence syndrome is seen only in 
mammals and mostly in higher mammals. For work of this kind, the mouse, guinea pig, rabbit and cat are quite useless. In the rat, an abstinence syndrome can be produced, but it is far less well developed than it is in monkeys and in man In dogs, there is a withdrawal syndrome that is well developed, but actions on the GI tract in that species are so marked that serious interference with nutrition can occur, and this prevents the long-term administration of morphine. Other species of monkey besides Macaca mulatta have been used successfully for the production of morphine physical dependence, but not all monkey species are satisfactory For example, some years ago in our laboratory, we tried to use the African green monkey, the grivet, but found it to be too excitable and difficult to train Therefore, we have stayed with Macaca mulatta

Upon completion of Single Dose Suppression and related tests, a report of the results is sent to the Committee on Problems of Drug Dependence, and from there it is forwarded to the manufacturer Once each year, the Committee provides us with the chemical structures of the drugs which we have tested, and this information is incorporated into our annual report, which is published each year in the Proceedings of the annual scientific meeting of the Committee on Problems of Drug Dependence

Occasionally, after he has received our report, a drug manufacturer may contact us with questions about our results or requests for additional tests The most commonly requested additional test is the Primary Addiction Study (PAS) of which we perform approximately six each year.

In a PAS, we take monkeys which are not dependent upon any drug, and over a period of approximately one month we give them progressively larger doses of the test drug, usually on an every-6-hr injection schedule. On the 14th and 16th days of test drug administration, the animals are challenged with nalorphine and naloxone, respectively, to see whether precipitated abstinence signs can be produced These nalorphine and naloxone challenges are repeated on the 28th and 30th days, respectively On approximately the 33rd day of the study, the administration of the test drug is discontınued abruptly, and the animals are observed for signs of natural withdrawal.

Primary Addiction Studies emphasize the importance, in the production of physical dependence, of the duration of action of a drug with respect to the administration interval A very short-acting drug (e.g. fentanyl), which is highly effective in suppressing the signs of morphine physical dependence, produces practically no physical dependence of its own when it is given every $6 \mathrm{hr}$ for one month Likewise, you cannot produce much dependence to meperidine (pethidıne) if you administer it every $6 \mathrm{hr}$, though you can show dependence if you reduce the injection interval to $3 \mathrm{hr}$

In SDS and PAS experiments, the monkey has no choice in the matter, he is captured and injected with a drug. However, this is not the case with our selfinjection animals These monkeys have been prepared surgically with a plastic catheter inserted into the superior vena cava with its tip at the level of the right atrium of the heart The catheter exits from the animal via a skin incision between the scapulae The animal wears a harness which is connected to the wall of the cage by a hinged, hollow tube through which the catheter passes to a pump behind the cage The pump delivers drug solution from a reservoir, through the catheter to the monkey at appropriate tumes

The animal works on a fixed-ratio schedule of 30 presses of a lever to receive one intravenous injection of drug solution (an FR 30 schedule) Normally the animal works for codeine in a dose of $03 \mathrm{mg} / \mathrm{kg} / \mathrm{injection}$ for two $1-\mathrm{hr}$ sessions each day For codeine, the monkey will maintain a rate of lever-pressing between 2.0 and 2.5 responses/sec for the hour At every fourth session, either saline or a test drug is substituted for codeine, and the response rate is measured For salıne, the response rate approaches zero; for active, morphine-like drugs, the dose-response relationship is an inverted $U$-shaped curve. (That is to say, for morphine and many other active drugs, there is a concentration below which the animal behaves as if it were saline and will not work for it, there is an optımal concentration of drug at which the monkey's 
response rate may approach that seen with codeıne; and above that optımal concentration of drug, the response falls off toward zero )

In the self-administration test, the monkeys will press a lever to receive the standard narcotic agents-morphıne, codeine, meperidıne, methadone, heroin, etc. They will not work for the so-called kappa receptor agonists, ketocyclazocine and ethylketocyclazocine. For the mixed agonist-antagonists, the answer is sometimes 'yes' and sometimes 'no'; they will not work for nalorphine or naloxone, they will give a few responses for propıram, and they will work energetıcally for buprenorphine The monkeys will work for a variety of non-narcotic drugs-barbiturates and alcohol, cocaine and amphetamine. They will not work for chlorpromazine or for LSD. With diazapam, the results are equivocal: Yanagita has been able to get the monkey to work for the benzodiazepine, while other workers with slightly different experımental conditions have obtained negative results.

At the present time, the future of this dependence evaluation program is quite uncertain in the United States. Several factors which are involved are-

(a) The Committee on Problems of Drug Dependence is no longer affiliated with the National Academy of Sciences-National Research Council. On July 1, 1976 it became a free-standing committee

(b) The Addiction Research Center at Lexington, Kentucky no longer uses human volunteers to test the drugs which have passed the Michigan screen. The use of prisoner addicts ended on January 1, 1977

(c) Our Food and Drug Admınistration has not decided what kind of prechnical testıng will be required for potent analgesics in the future, though it is safe to say that some form of dependence evaluation will be demanded for a long tume to come.

Thus, we seem to be at the end of an era-the era of Nathan B Eddy. A new era will soon begin, but we do not know what criteria will be selected and what tests will be required by governments which are seekıng to protect their citizens from enslavement by dependence-producing drugs. 